\title{
Knockdown of human antigen $R$ reduces the growth and invasion of breast cancer cells in vitro and affects expression of cyclin D1 and MMP-9
}

\author{
ZHU YUAN ${ }^{1,2}$, ANDREW J. SANDERS ${ }^{1}$, LIN YE $^{1}$, YU WANG $^{2}$ and WEN G. JIANG ${ }^{1}$ \\ ${ }^{1}$ Metastasis and Angiogenesis Research Group, Cardiff University School of Medicine, Cardiff, UK; ${ }^{2}$ Department of \\ General Surgery, Beijing Friendship Hospital, Capital University of Medical Science, Beijing 10050, P.R. China \\ Received December 16, 2010; Accepted February 11, 2011
}

DOI: $10.3892 /$ or.2011.1271

\begin{abstract}
HuR, a ubiquitously expressed member of the $\mathrm{Hu}$ family, selectively binds and stabilizes ARE-containing mRNAs encoding proto-oncogenes, cell cycle regulators, cytokines and growth factors. The role of HuR and its cellular function in breast cancer remains unclear. This study aimed to provide new insights into the implication of HuR in breast cancer. We show that MCF7 and MDA-MB-231 breast cancer cells stably transfected with a hammerhead ribozyme transgene specifically targeted to $\mathrm{HuR}$ (MCF7 ${ }^{\text {HuRKO }}$ and MDA-MB-231 ${ }^{\text {HuRKO}}$ ) have reduced HuR expression both at mRNA and protein levels. This study reveals that HuR knockdown dramatically reduced cell growth in MCF7 cells $(\mathrm{P}<0.001)$ and invasive properties in MDA-MB-231 cells $(\mathrm{P}<0.001)$. Furthermore, we report that the decreased cell growth rate in MCF7 cells is seen together with a reduction in cyclin D1 transcript and protein levels and that the change in invasiveness in MDA-MB-231 cells seems to be linked with decreased MMP-9 levels. Our study shows that targeting HuR can influence breast cancer cell growth and invasion and suggests a role for HuR in vitro in enhancing breast cancer cell growth and invasion. These changes may be facilitated through changes in the levels of cyclin D1 and MMP-9.
\end{abstract}

\section{Introduction}

The human ( $\mathrm{Hu}$ ) antigen $\mathrm{R}(\mathrm{HuR})$, a ubiquitously expressed member of the $\mathrm{Hu}$ family of RNA-binding proteins, was first cloned and identified in 1996 (1) and the human HuR gene was found to be localized to human chromosome 19 p13.2 (2). The Hu protein family comprises four vertebrate members, the primarily neuronal proteins $\mathrm{HuB}$ (Hel-N1), HuC

Correspondence to: Professor Wen G. Jiang, Metastasis and Angiogenesis Research Group, Department of Surgery, Cardiff University School of Medicine, Heath Park, Cardiff CF14 4XN, UK E-mail: jiangw@cf.ac.uk

Key words: human antigen $\mathrm{R}$, breast cancer, growth, invasion, cyclin D1, MMP-9
(PLE21) and HuD, and the ubiquitously expressed $~ 34 \mathrm{kDa}$ protein $\mathrm{HuR}(2)$. As members of the Hu protein family share homology with the Drosophila embryonic lethal abnormal vision (ELAV) proteins, they are sometimes regarded as the $\mathrm{Hu} / \mathrm{elav}$ family (3). In humans, HuR is widely expressed in all proliferating cells, whereas $\mathrm{HuB}, \mathrm{HuC}$ and $\mathrm{HuD}$ are expressed in terminally differentiated neurons and are therefore called the neuronal Hu proteins (4).

HuR protein contains three highly conserved RNA recognition motifs (RRMs) and a variable basic hinge region between its RRM2 and RRM3 $(5,6)$. RRM1 and RRM2 were found to bind and mediate the AU- and U-rich elements (collectively termed ARE) recognition (7) and RRM3 is believed to bind the poly (A) tail and help maintain the stability of the RNA-protein complex (8). The less conserved hinge region is believed to contain sequences that allow HuR to shuttle between the nucleus and cytoplasm (6).

HuR has a variety of biological functions, all of which are based on its ability to stabilize the labile mRNAs bearing the AU- and U-rich elements (ARE) and affect their expression (9). Many of such ARE-containing mRNAs encode protooncogenes, cell cycle regulators, cytokines and growth factors, which are important in many transient biological processes (10). The mechanism of HuR stabilization on target mRNAs is believed to be mediated through competition with destabilizing ARE-BPs. HuR is mainly localized within the cell nucleus and its presence in the cytoplasm appears to be intimately linked to its mRNA-stabilizing function, thus the nucleo-cytoplasm shuttling of HuR is generally assumed as the initial and critical step of its stabilizing effects $(1,11)$. HuR shuttling structurally relies on a sequence in the hinge region, which is denoted as HNS (HuR nucleocytoplasmic shuttling sequence) (12).

Numerous ARE-containing mRNAs encoding protooncogenes, cell cycle regulators, cytokines and growth factors have been reported either to associate with HuR or, further, to be post-transcriptionally regulated by HuR (6). Many of them encode functionally diverse proteins that are important in many transient biological processes including cell growth and differentiation, signal transduction, transcriptional and translational control, hematopoiesis, apoptosis, nutrient transport, and metabolism (10). However, the potential contribution of 
HuR to breast carcinogenesis and tumor progression has not been directly investigated. Our study provides new insights into the biological functions HuR and its role in breast cancer.

In the present study, we examined HuR expression in a series of human cancer cell lines. In order to elucidate the role and the cellular function of HuR in breast cancer, a ribozyme transgene consisting of hammerhead ribozyme and antisense specific to HuR was cloned into a pEF6 expression vector and transfected into MCF7 and MDA-MB-231 cells. The effects of HuR knockdown on the human breast cancer cells was examined through a series of in vitro tests.

\section{Materials and methods}

Cell lines and materials. Human MCF7 and MDA-MB-231 breast cancer cell lines and human PC-3 prostate cancer cell line were obtained from the American Type Culture Collection (ATCC, MD, USA). The ZR-751 cell line was purchased from the European Collection of Cell Cultures (ECACC, Salisbury, UK). The cells were routinely cultured in DMEM/Ham's F12 with L-Glutamine medium (PAA Laboratories, Somerset, UK), supplemented with antibiotics and $10 \%$ foetal calf serum (PAA Laboratories), and incubated at $37.0^{\circ} \mathrm{C}, 5 \% \mathrm{CO}_{2}$ and 95\% humidity. Monoclonal mouse anti-HuR (SC-5261), antiGAPDH (SC-32233), anti-MMP-9 (SC-21733), and polyclonal rabbit anti-cyclin D1 IgG (SC-8432) were obtained from Santa Cruz Biotechnology Inc. (Santa Cruz, CA, USA). Peroxidaseconjugated anti-mouse and anti-rabbit IgG were purchased from Sigma-Aldrich Ltd. (Poole, UK).

Generation of HuR knockdown in breast cancer cell lines. Anti-human HuR hammerhead ribozymes were designed based on the secondary structure of HuR mRNA, generated using the Zuker RNA mFold program (13). The ribozymes were synthesized and cloned into a pEF6/V5-His-TOPO plasmid vector (Invitrogen, Paisley, UK). Ribozyme transgenes and empty pEF6 control plasmids were transfected into MCF7 and MDA-MB-231 cells individually following a previously reported procedure $(14,15)$. Following transfection and blasticidin selection, cells were subsequently cultured in maintenance medium and routinely tested to confirm knockdown of HuR expression. MCF7 and MDA-MB-231 cells containing the ribozyme transgenes or the control pEF6 plasmids were designated as MCF7 ${ }^{\text {HuRKO }}$ and MCF7 ${ }^{\mathrm{pEF}}$, MDA-MB-231 ${ }^{\text {HuRKO }}$ and MDA-MB-231 ${ }^{\mathrm{pEF} 6}$, respectively. The wild-type cells were labelled as MCF-7 ${ }^{\mathrm{WT}}$ or MDA-MB-231 ${ }^{\mathrm{WT}}$.

RNA extraction and reverse transcription-polymerase chain reaction $(R T-P C R)$. RNA was extracted from cells using the TRI reagent (Sigma, Dorset, UK). Reverse transcription was carried out using the iScript ${ }^{\mathrm{TM}}$ cDNA synthesis kit (Bio-Rad, CA, USA). PCR conditions were: denaturing at $94^{\circ} \mathrm{C}$ for $40 \mathrm{sec}$, annealing at $55^{\circ} \mathrm{C}$ for $40 \mathrm{sec}$ and extension at $72^{\circ} \mathrm{C}$ for $80 \mathrm{sec}$. PCR was conducted over 36 cycles with an initial 5 min denaturing step $\left(94^{\circ} \mathrm{C}\right)$ and a final 10 min extension step $\left(72^{\circ} \mathrm{C}\right)$. PCR products were separated on an agarose gel. Primer sequences are provided in Table I.

Quantitative-polymerase chain reaction $(Q-P C R)$. Real-time quantitative PCR was also used to assess the HuR transcript levels present in the control and transfected cell lines as previously reported (16). Briefly, the iCycler IQ system was used to detect and quantify the number of HuR transcripts in each of the control and transfected cells. Transcript copy numbers were obtained based on an internal standard and normalized against GAPDH levels in these samples. Conditions for Q-PCR were: an initial $15 \mathrm{~min} 95^{\circ} \mathrm{C}$ period followed by 80 cycles of $95^{\circ} \mathrm{C}$ for $15 \mathrm{sec}, 55^{\circ} \mathrm{C}$ for $60 \mathrm{sec}$ and $72^{\circ} \mathrm{C}$ for $20 \mathrm{sec}$.

SDS-PAGE and Western blotting. Following lysis of cells, equal amount of each samples were separated on a $10 \%$ acrylamide gel. Proteins were probed using the respective primary antibodies at a concentration of 1:300 (HuR) and 1:500 (GAPDH) and specific peroxidase conjugated secondary antibodies at a concentration of 1:1000. Protein bands were documented using a gel documentation system (UVITech, Cambridge, UK).

Immunocytochemical staining. Following overnight incubation, cells were fixed and then permeabilized with $0.1 \%$ Triton X100 for $5 \mathrm{~min}$ in TBS. Following blocking with horseserum in Super Sensitive ${ }^{\mathrm{TM}}$ Wash Buffer (BioGenex, USA), immunochemical staining was performed using the primary antibody at a concentration of 1:100 and Vectastain Universal Elite ABC kit (Vectastain ${ }^{\circledR}$ ABC system, Vector Laboratories, Inc., Nottingham, UK). Intensity of the staining was quantified by using the area morphometry of the Optimas image analysis software (Optimas version 6.0, Optimas, WA, USA).

In vitro growth assay. Cells were incubated for 1, 3 and 5 days before being fixed in $4 \%$ formaldehyde (v/v) and stained with $0.5 \%(\mathrm{w} / \mathrm{v})$ crystal violet. The crystal violet stain was then extracted using $10 \%$ acetic acid (v/v) and cell density was determined by measuring the absorbance of this solution at a wavelength of $540 \mathrm{~nm}$ using an ELx800 spectrophotometer (Bio-Tek Instruments Inc., Winooski, VT, USA).

In vitro Matrigel invasion assay (17). Briefly, 15,000 cells were seeded into trans-well inserts (Becton Dickinson Labware, NJ, USA), containing $8.0 \mu \mathrm{m}$ pores, which had been coated with $50 \mu \mathrm{g}$ /insert of Matrigel Matrix Basement Membrane (BD Biosciences, Oxford, UK). After $72 \mathrm{~h}$ of incubation, cells which had invaded through the artificial basement membrane to the outside of the trans-well insert were stained and counted.

In vitro Matrigel adhesion assay (18). Briefly, 45,000 cells were seeded into the wells of a 96-well plate that had been pre-coated with $5 \mu \mathrm{g}$ of Matrigel. After $45 \mathrm{~min}$ of incubation, non-adherent cells were removed by vigorous washing. Adherent cells were then stained and counted.

In vitro migration/wound healing assay (19). Cells were cultured in a 24-well plate, upon reaching confluence; the cell monolayer was wounded using a $21 \mathrm{G}$ needle. Digital images of a set area were taken using a GXCAM-5 scientific imaging camera (GTVision, Suffolk, UK) every $15 \mathrm{~min}$ for a $90-\mathrm{min}$ period. Cell migration into the wound was then calculated using ImageJ analysis software. 
Table I. Primers used for RT-PCR or Q-PCR in the present study.

\begin{tabular}{|c|c|c|c|}
\hline $\begin{array}{l}\text { Gene of } \\
\text { interest }\end{array}$ & Primer name & Primer sequence $\left(5^{\prime}-3^{\prime}\right)$ & $\begin{array}{l}\text { Optimal annealing } \\
\text { temperature }\left({ }^{\circ} \mathrm{C}\right)\end{array}$ \\
\hline HuR & $\begin{array}{l}\text { HuR-F8 } \\
\text { HuR-R8 }\end{array}$ & $\begin{array}{l}\text { gagctcagaggtgatcaaag } \\
\text { ttgtagatgaaaatgcacca }\end{array}$ & 55 \\
\hline HuR Ribozyme 1 & $\begin{array}{l}\text { HuRrib1F } \\
\text { HuRrib1R }\end{array}$ & $\begin{array}{l}\text { ctgcagcatacgacaccttaatggttttctgatgagtccgtgagga } \\
\text { actagtgaacggettgaggctccagtttcgtcctcacggact }\end{array}$ & 55 \\
\hline HuR Ribozyme 2 & $\begin{array}{l}\text { HuRrib2F } \\
\text { HuRrib2R }\end{array}$ & $\begin{array}{l}\text { ctgcagctcgggcgagcatacctgatgagtccgtgagga } \\
\text { actagtcaaaaaccattaaggtgtttcgtcctcacggact }\end{array}$ & 55 \\
\hline HuR Ribozyme 3 & $\begin{array}{l}\text { HuRrib3F } \\
\text { HuRrib3R }\end{array}$ & $\begin{array}{l}\text { ctgcaggacccgcgagttgatctgatgagtccgtgagga } \\
\text { actagttctctcggtttgggcggatttcgtcctcacggact }\end{array}$ & 55 \\
\hline HuR Ribozyme 4 & $\begin{array}{l}\text { HuRrib4F } \\
\text { HuRrib4R }\end{array}$ & $\begin{array}{l}\text { ctgcagatccacgaggacccgcgagttctgatgagtccgtgagga } \\
\text { actagtcggtttgggcggatcatttcgtcctcacggact }\end{array}$ & 55 \\
\hline GAPDH & $\begin{array}{l}\text { F8 } \\
\text { R8 }\end{array}$ & $\begin{array}{l}\text { ggctgcttttaactctggta } \\
\text { gactgtggtcatgagtcctt }\end{array}$ & 55 \\
\hline GAPDH (Q-PCR) & $\begin{array}{l}\text { GAPDH F2 } \\
\text { GAPDH ZR2 }\end{array}$ & $\begin{array}{l}\text { ctgagtacgtcgtggagtc } \\
\text { actgaacctgaccgtacacagagatgaccetttg }\end{array}$ & 55 \\
\hline Cyclin D1 & $\begin{array}{l}\text { Cyclin D1 F1 } \\
\text { Cyclin D1 ZR } \\
\text { Cyclin D1 R1 }\end{array}$ & $\begin{array}{l}\text { cggtgtcctacttcaaatgt } \\
\text { actgaacctgaccgtacaaagcggtccaggtagttc } \\
\text { acctcctcctcctcctct }\end{array}$ & 55 \\
\hline MMP-9 & $\begin{array}{l}\text { MMP-9 F1 } \\
\text { MMP-9 R1 } \\
\text { MMP-9 ZR1 }\end{array}$ & $\begin{array}{l}\text { aactacgaccgggacaag } \\
\text { attcacgtcgtccttatgc } \\
\text { actgaacctgaccgtacaggaaagtgaaggggaaga }\end{array}$ & 55 \\
\hline
\end{tabular}

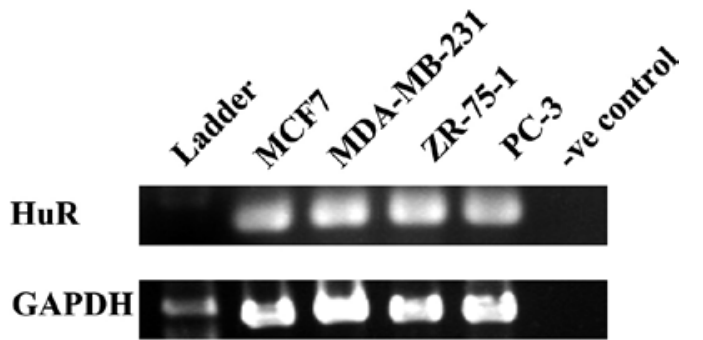

Figure 1. Expression of HuR in breast and prostate cancer cell lines. The presence of HuR was examined in 4 human cancer cell lines using RT-PCR. HuR was highly expressed in all breast (MCF7, MDA-MB-231 and ZR-751) and prostate (PC-3) cell lines tested.

Statistical analysis. Experimental procedures were repeated independently as least 3 times. Data were analysed using the Minitab 14 software and statistical comparisons were drawn using the two-sample, two-tailed t-test or the Mann-Whitney non-parametric test.

\section{Results}

The expression of HuR in breast cancer cell lines. The presence of HuR was examined in 4 human cancer cell lines through reverse transcription-PCR (RT-PCR). The expression of HuR was relatively high in the breast cell lines (MCF7,
MDA-MB-231 and ZR-75-1) and the prostate cancer cell line (PC-3) examined (Fig. 1). To investigate the biological function of HuR in breast cancer, two of the examined cell lines were chosen for knockdown studies. MCF7 cells are derived from a metastatic pleural effusion of a female patient with breast cancer. MCF7 is an adherent cell line with an epithelial morphology and is estrogen receptor positive. The MDA-MB-231 cell line is derived from a pleural effusion of a female patient with metastatic breast cancer. MDA-MB-231 cells are adherent and epithelial in morphology. The cell line is estrogen receptor negative and is highly tumorigenic.

Manipulation of HuR expression by ribozyme transgene. RT-PCR and Q-PCR demonstrated that HuR mRNA expression was successfully knocked down in MCF $7^{\text {HuRKO }}$ and MDA-MB$231^{\text {HuRKO }}$ cells in comparison to the level of expression in wild-type cells (MCF7 ${ }^{\mathrm{WT}}$ and MDA-MB-231 ${ }^{\mathrm{WT}}$ ) and in empty plasmid cells (MCF7 ${ }^{\mathrm{pEF} 6}$ and MDA-MB-231 ${ }^{\mathrm{pEF} 6}$ ) (Fig. 2A and B). Additionally, Western blotting was used to probe for HuR protein levels in both the control and transfected cell lines. Similar to the trends seen at the mRNA level, HuR protein was found to be highly expressed in all of the control cell lines $\left(\mathrm{MCF}^{\mathrm{WT}}, \mathrm{MDA}-\mathrm{MB}-231^{\mathrm{WT}}, \mathrm{MCF}^{\mathrm{pEF} 6}\right.$ and MDA-MB-231 ${ }^{\mathrm{pEF} 6}$ ) and expression of $\mathrm{HuR}$ protein exhibited a dramatic reduction in the transfected cell lines (MCF7 ${ }^{\mathrm{HuRKO}}$ and MDA-MB-231 ${ }^{\mathrm{HuRKO}}$ ) (Fig. 2C). Immunocytochemical (ICC) staining indicated a decrease in HuR protein levels in both MDA-MB-231 and 

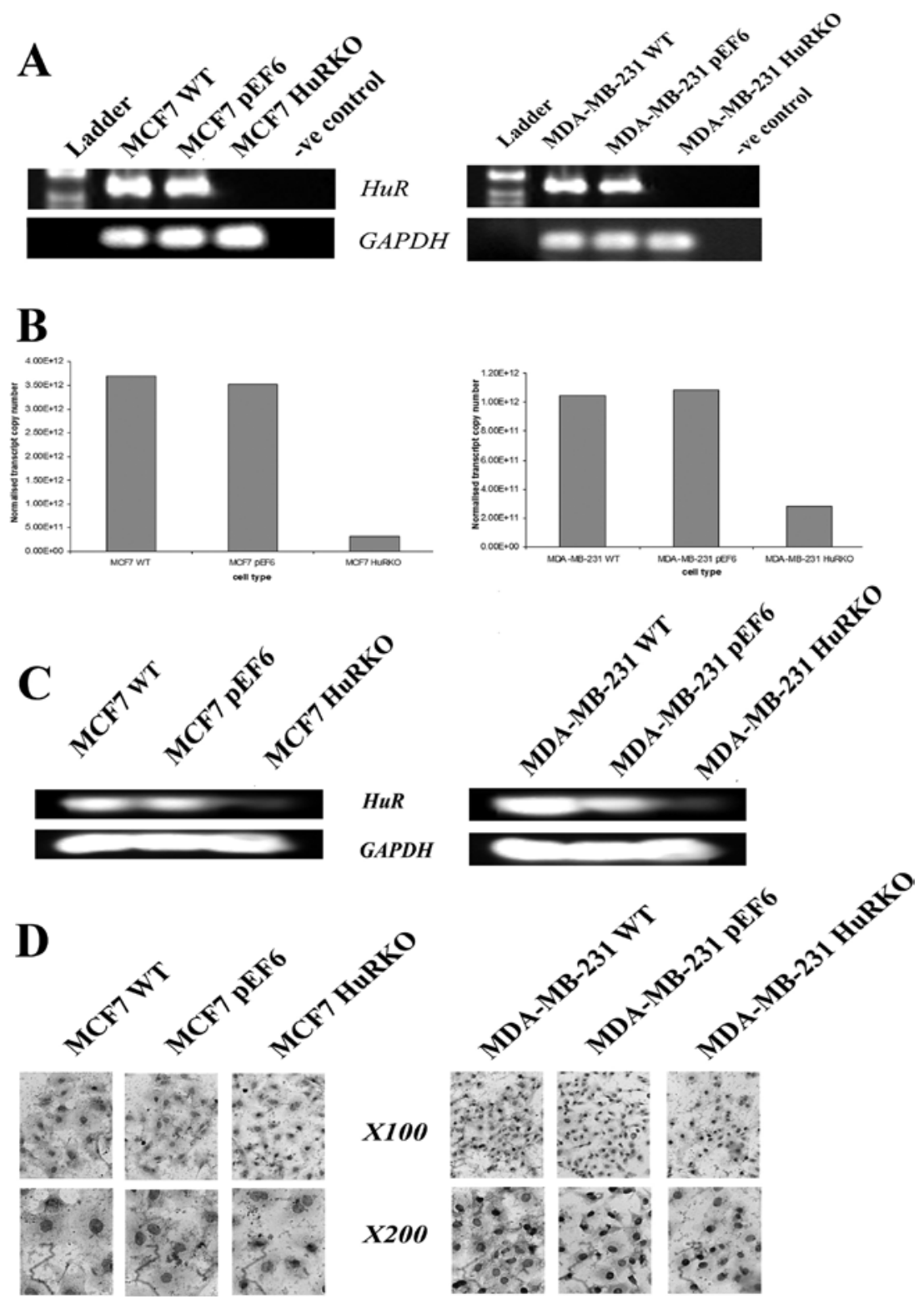

Figure 2. Transfection with HuR ribozyme transgene successfully reduced levels in MCF7 and MDA-MB-231 breast cancer cell lines. (A) HuR mRNA was qualitatively detected using RT-PCR and demonstrated a reduction in HuR expression in MCF7 ${ }^{\text {HuRKO }}$ and MDA-MB-231 ${ }^{\text {HuRKO }}$ cells compared to controls. (B) Q-PCR was subsequently used to confirm the decrease of HuR mRNA transcript in MCF7 ${ }^{\text {HuRKO }}$ and MDA-MB-231 $1^{\text {HuRKO }}$ cell lines. (C) Western blotting showed a similar decrease in HuR protein levels in the MCF7 ${ }^{\text {НиRKO }}$ and MDA-MB-231 $1^{\text {HuRKO }}$ in comparison to controls. (D) Immunocytochemical staining indicated HuR protein levels were decreased by the ribozyme transgene.

MCF7 cells transfected with the ribozyme transgene versus their respective controls (Fig. 2D).

HuR has differing effects on cell growth. Effects of HuR on the growth of MCF7 and MDA-MB-231 were examined using an in vitro tumor cell growth assay. Contrasting results for the effects of HuR expression on tumor cell growth were seen between the MCF7 and MDA-MB-231 cell lines. In the MCF7 cell line, knockdown of HuR resulted in a significant decrease in growth and a significant difference was seen between the $\mathrm{MCF}^{\mathrm{HuRKO}}$ and $\mathrm{MCF}^{\mathrm{pEF} 6}$ cell line after 3- and 5-day incubation periods (day 3: 62.5 \pm 21.2 vs. $249.7 \pm 48.4$ $\mathrm{P}<0.001$, day 5: $163.6 \pm 35.4$ vs. $416.5 \pm 42.9 \mathrm{P}<0.001$ ) (Fig. $3 \mathrm{~A})$. Strangely, the MDA-MB-231 cell line did not follow a similar trend and no significant difference in growth was seen between the MDA-MB-231 ${ }^{\text {HuRKO }}$ and MDA-MB-231 ${ }^{\mathrm{pEF} 6}$ cell lines over the 5-day incubation period (day 3: $284.1 \pm 14.8$ vs. $301.0 \pm 53.5$ $\mathrm{P}>0.05$, day 5: $866.2 \pm 67.7$ vs. $719.3 \pm 76.7$ P>0.05) (Fig. 3B).

HuR expression does not alter cell adhesion. The capacity of MCF7 and MDA-MB-231 breast cancer cells to adhere to an artificial Matrigel basement membrane over a 45-min period was examined using an in vitro Matrigel adhesion assay. Transfection with the HuR ribozyme transgene plasmids was not seen to affect the adhesive properties of either MCF7 or MDA-MB-231 cells to an artificial Matrigel basement membrane over a 45-min incubation period (Fig. 3C and D). No significant difference in adhesive capacity was seen between cells containing the ribozyme transgene plasmids and their respective pEF6 control cells (MCF $7^{\mathrm{HuRKO}}$ vs. MCF ${ }^{\mathrm{pEF} 6}$, $18.25 \pm 2.96$ vs. $17.13 \pm 2.70, \mathrm{P}>0.05$; MDA-MB-231 ${ }^{\text {HuRKO }}$ vs. MDA-MB-231 ${ }^{\mathrm{pEF} 6}, 57.88 \pm 8.71$ vs. $\left.67.38 \pm 9.93, \mathrm{P}>0.05\right)$. 

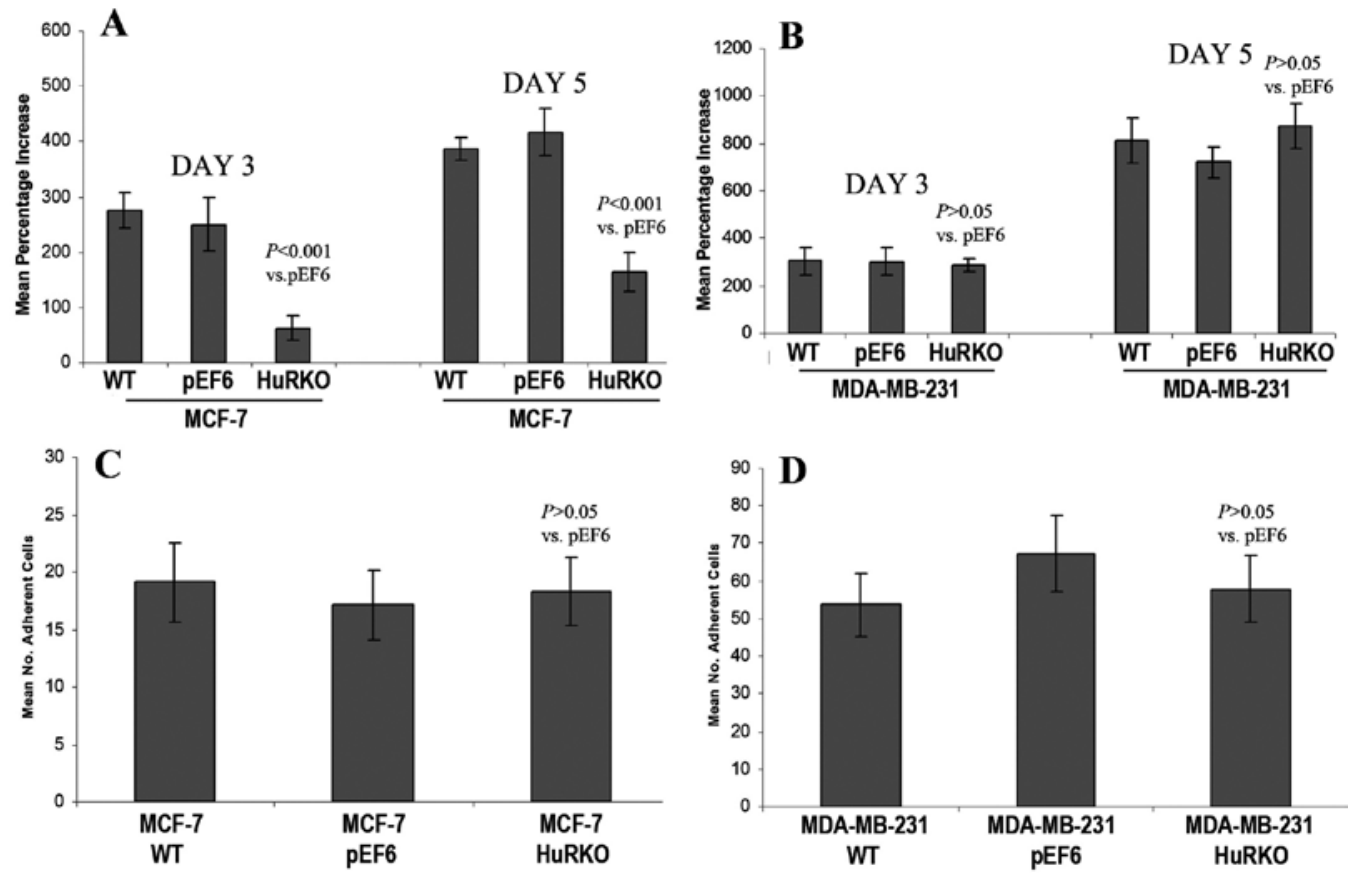

Figure 3. Impact of HuR suppression on cell growth and adhesion of MCF7 and MDA-MB-231 cells. (A) Knockdown of HuR significantly reduced the growth rate of MCF7 cells $(\mathrm{P}<0.001)$. (B) In contrast, knockdown of HuR did not affect the growth of MDA-MB-231 cells. (C and D) Knockdown of HuR was not seen to affect the adhesion of MCF7 and MDA-MB-231 cells.
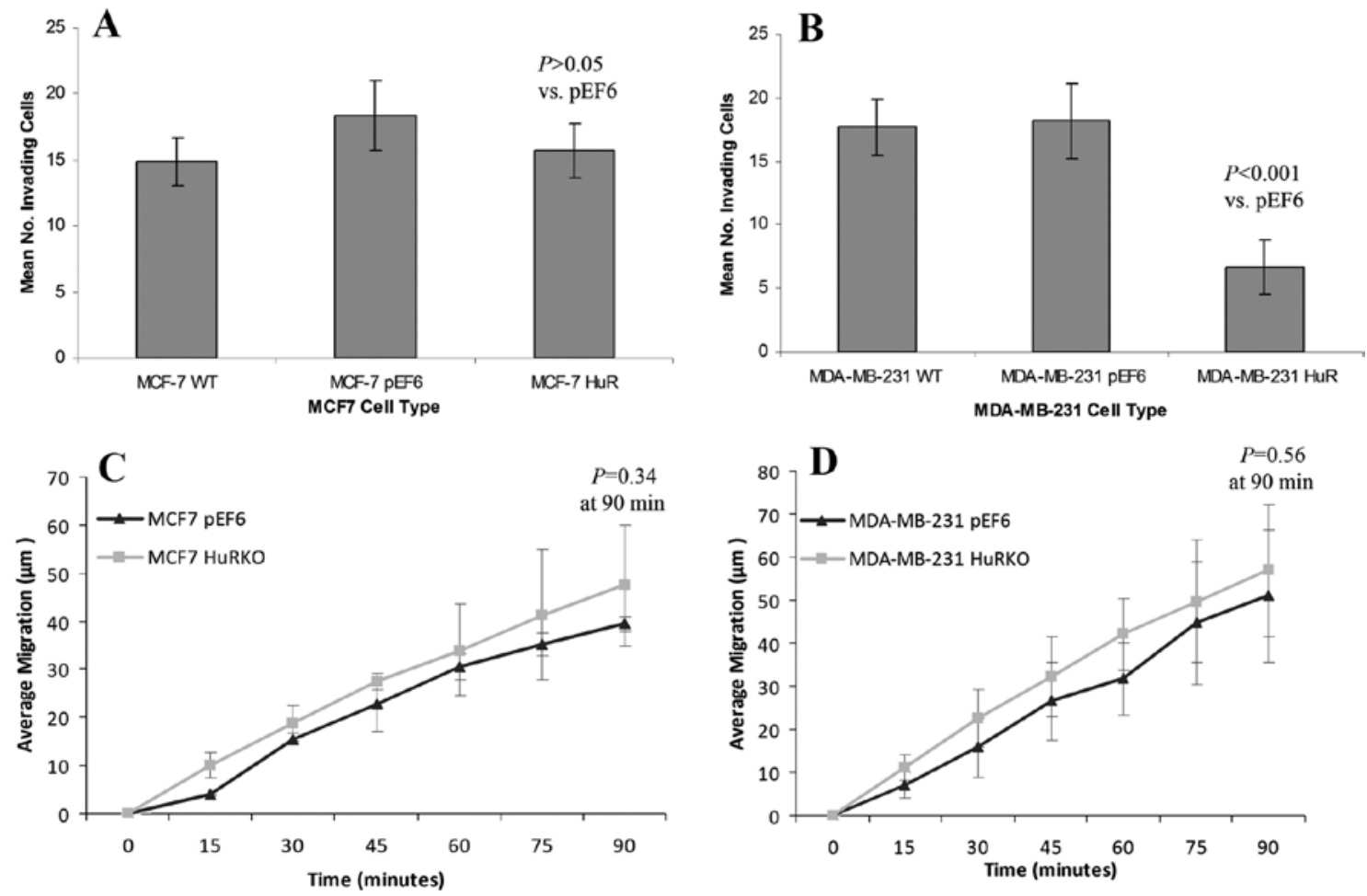

Figure 4. Impact of HuR suppression on cellular invasion and migration of MCF7 and MDA-MB-231 cells. (A) No significant difference in cellular invasion was seen between MCF7 $7^{\text {HuRKO }}$ and $\mathrm{MCF} 7^{\mathrm{pFF}}$ cell lines over the 3-day incubation period (P>0.05). (B) In contrast, knockdown of HuR significantly reduced the invasiveness of MDA-MB-231 cells compared to the control $(\mathrm{P}<0.001)$. (C and D) Knockdown of HuR did not retard the migration of either MCF7 or MDA-MB-231 cells.

Loss of endogenous HuR results in differing cell invasion. No significant difference in cellular invasion was seen between the $\mathrm{MCF}^{\mathrm{HuRKO}}$ and MCF $7^{\mathrm{PEF} 6}$ cell lines over the 3-day incubation period $(15.67 \pm 2.07$ vs. $18.33 \pm 2.66, \mathrm{P}>0.05)$ (Fig. $4 \mathrm{~A}$ ).
In contrast, loss of endogenous HuR resulted in a dramatic reduction in the invasiveness of MDA-MB-231 cells (Fig. 4B). MDA-MB-231 ${ }^{\text {HuRKO }}$ was found to have a significantly reduced capacity to invade through an artificial Matrigel basement 

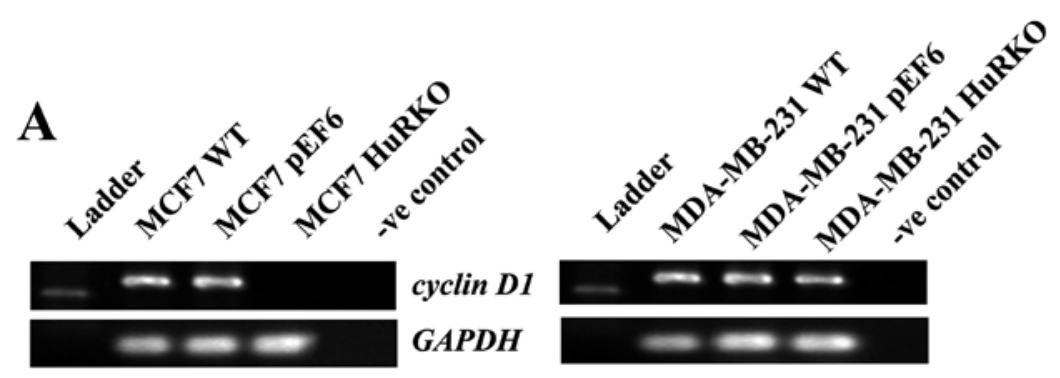

B


Figure 5. Knockdown of HuR can impact on Cyclin D1 levels. Cyclin D1 transcription was down-regulated with loss of endogenous HuR expression in MCF7 cells. (A-C) Conventional RT-PCR, Q-PCR and Western blotting reveal lower mRNA and protein levels of cyclin D1 in MCF7 $7^{\text {HuRKO }}$ cells compared to $\mathrm{MCF}^{\mathrm{WT}}$ and MCF7 ${ }^{\mathrm{PEF}}$ cells. (D) There was decreased ICC staining of cyclin D1 in MCF $7^{\mathrm{HuRKO}}$ cells compared with that in MCF7 ${ }^{\mathrm{WT}}$ and MCF7 $7^{\mathrm{pEF}}$. No similar trend of cyclin D1 at mRNA and protein levels was seen in MDA-MB-231 cell lines.

membrane compared to its respective control cells $(6.67 \pm 2.16$ vs. $18.17 \pm 2.93, \mathrm{P}<0.001)$.

Knockdown of HuR does not influence cell migration. The effect of HuR expression on cell migration was assessed using a migration/wounding assay. Knockdown of HuR did not influence the migration of either MCF7 or MDA-MB-231 cells (Fig. 4C and D). No significant difference in migratory rates was seen between either MCF $7{ }^{\mathrm{HuRKO}}$ or MDA-MB$231^{\text {HuRKO }}$ and their respective pEF6 controls (MCF7 $7^{\text {HuRKO }}$ vs. $\mathrm{MCF} 7^{\mathrm{pEF} 6}, 47.4 \pm 12.7$ vs. $39.36 \pm 1.66, \mathrm{P}=0.34$ at $90 \mathrm{~min}$; MDA-MB-231 $1^{\mathrm{HuRKO}}$ vs. MDA-MB-231 $1^{\mathrm{pEF} 6}, 56.85 \pm 4.94$ vs. $51.0 \pm 15.5, \mathrm{P}=0.56$ at $90 \mathrm{~min}$ ).
Knockdown of HuR correlates with down-regulation Cyclin D1. Cyclin D1, as a target mRNA of HuR, is one of the more frequently altered cell cycle regulators in cancers (20), thus, we assumed an association of HuR's effect on tumor cell growth with the cell cycle regulator cyclin D1, and we examined the cyclin D1 expression at mRNA and protein level in both the control and transfected breast cancer cells. Our study showed that cyclin D1 transcription was down-regulated with loss of endogenous HuR expression in MCF7 cells. Conventional RT-PCR, Q-PCR and Western blot revealed lower mRNA and protein levels of cyclin D1 in MCF7 $7^{\text {HuRKO }}$ cells compared to $\mathrm{MCF}^{\mathrm{WT}}$ and MCF7 ${ }^{\mathrm{pEF} 6}$ cells (Fig. 5A-C). There was decreased ICC staining of cyclin D1 in MCF $7^{\text {HuRKO }}$ 


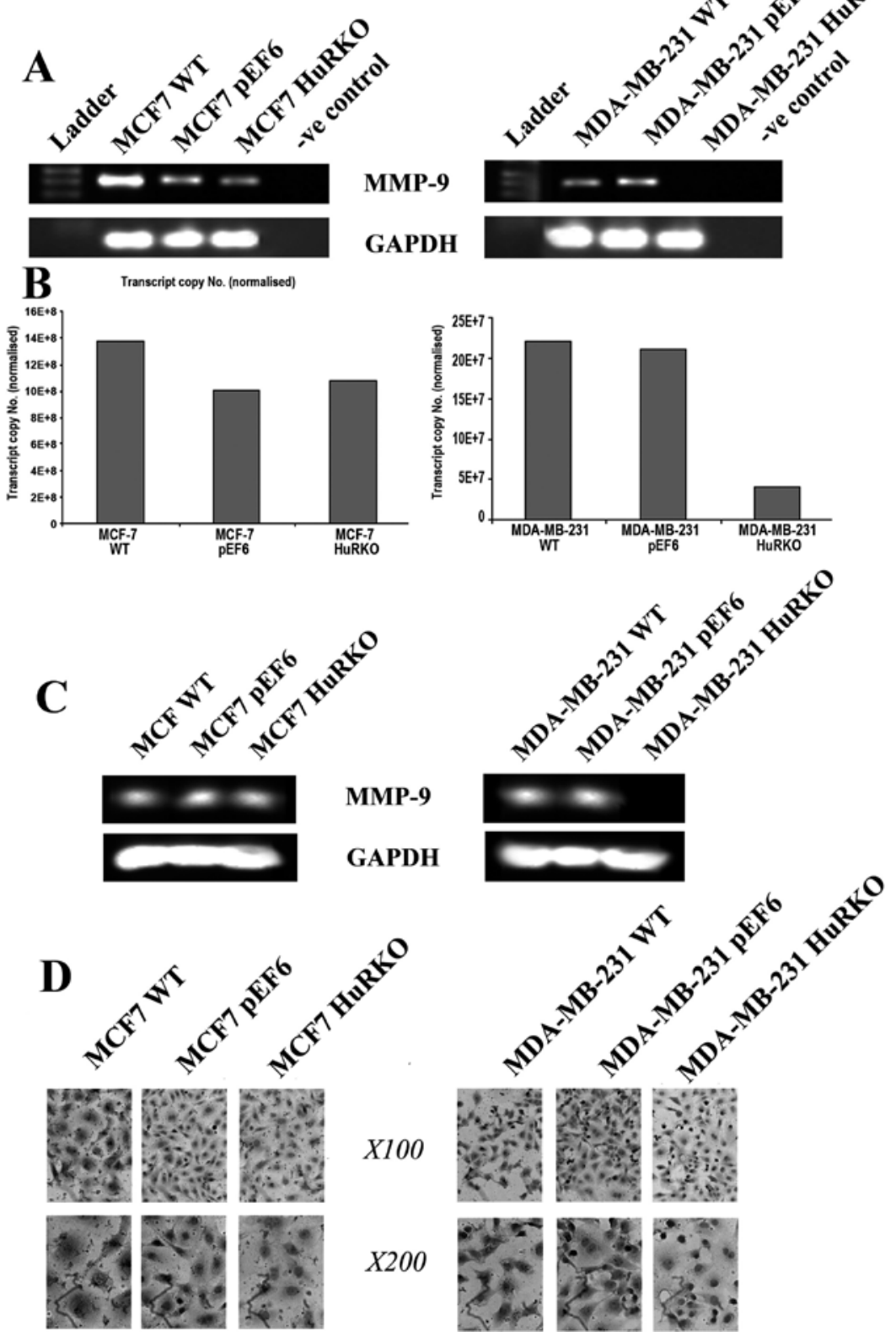

Figure 6. Knockdown of HuR can impact on MMP-9 levels. (A-C) A decreased level of MMP-9 mRNA and protein was observed in MDA-MB-231 cells containing the HuR ribozyme transgene. (D) ICC staining revealed a decreased staining intensity of MMP-9 in MDA-MB-231 ${ }^{\mathrm{HuRKO}}$ cells compared with that in MDA-MB-231 $1^{\mathrm{WT}}$ and MDA-MB-231 ${ }^{\mathrm{EFF}}$. No similar reduction of MMP-9 expression at mRNA and protein levels was seen in MCF $7^{\mathrm{HuRKO}}$ cells compared to its respective wild-type and pEF6 control cells.

cells, compared with that in MCF7 ${ }^{\mathrm{WT}}$ and $\mathrm{MCF} 7^{\mathrm{pEF} 6}$ (Fig. 5D). No similar trend of cyclin D1 at mRNA and protein levels was seen in MDA-MB-231 cell lines (Fig. 5).

Knockdown of HuR correlates with reduction of MMP-9. Previous studies have indicated the importance of MMP-9 in cancer cell invasion and metastasis (21). In order to gain insight into mechanisms whereby HuR may promote breast cancer cell invasion, we examined the levels of MMP-9 expression at both transcript and protein level in control and HuR suppressed breast cancer cells. A decreased level of MMP-9 mRNA was observed in MDA-MB-231 cells containing the HuR ribozyme transgenes. Concordant with this decrease in mRNA level, there was a decreased protein level (Fig. 6A-C). Decreased ICC staining of MMP-9 is also seen in MDA-MB-231 ${ }^{\text {HuRKO }}$ cells, compared with that in MDA-MB-231 ${ }^{\mathrm{WT}}$ and MDA-MB-231 $1^{\mathrm{pEF} 6}$ (Fig. 6D). Interestingly, no similar reduction of MMP-9 expression at mRNA and protein levels was seen in MCF7 ${ }^{\text {HuRKO }}$ cells compared to the respective wild-type and pEF6 control cells (Fig. 6).

\section{Discussion}

Normal human cells become neoplastic by progressively acquiring mutations in cancer genes, these mutations subsequently provide the cell with a competitive growth advantage via different cancer-cell phenotypes $(22,23)$. A variety of target 
mRNAs bound and stabilized by HuR are related to cancer. Many of such target mRNAs encode cell cycle regulators and proto-oncogenes such as cyclin A, cyclin B1, cyclin D1, c-myc and c-fos (24-26), growth factors such as EGF (27) and GM-CSF (28), as well as other factors and cytokines that influence tumour progression such as HIF-1 $\alpha$ (27), VEGF (29), uPA (30), MMP-9 and MTA1 (31). Through its association with such target mRNAs, HuR is found to play a pivotal role in the carcinogenesis and subsequent progression via diverse cancer-cell phenotypes: enhanced cell division, resistance of apoptosis, maintenance of angiogenesis, invasion of tissues and metastasis, and evasion of antitumor immune responses (32).

Despite HuR's ability to bind to and enhance the expression of mRNAs that play pivotal roles in cell growth and proliferation, transcriptional and translational control, hematopoiesis and apoptosis, its potential contribution to carcinogenesis and tumor progression in breast cancer has not been directly investigated. In order to elucidate the functional importance of HuR in breast cancer, our studies have led to the generation of human breast cancer cell lines (MCF7 and MDA-MB231) containing anti-human HuR hammerhead ribozyme transgenes and a reduced expression of HuR transcript and protein levels.

The present study shows that knockdown of HuR significantly decreased the growth rate of MCF7 cells over a 5-day incubation period; however, this trend was not mimicked in the MDA-MB-231 cells. Additionally, we demonstrate that HuR knockdown resulted in a dramatic reduction of the cellular invasiveness of MDA-MB-231 cells; however, the same trend was not seen in MCF7 cells. The exact reason behind this differential effect of HuR on the growth and invasion of these two breast cancer cell lines is currently unknown. It is likely that the differential growth effects may be due to differences in the expression patterns of other proteins between the MCF7 and MDA-MB-231 cell lines. We also report that knockdown of HuR does not alter the adhesive properties and migration capability of the two breast cancer cell lines.

In order to gain insight into the mechanisms whereby HuR may have its promoting effect on breast cancer cell growth, a series of growth factors and known target mRNAs of HuR were examined in MCF7 and MDA-MB-231 cells with and without the ribozyme transgenes. The data shows that the expression of cyclin D1 is correlated to HuR expression at mRNA and protein levels in the MCF7 cell line. However, no such correlation of cyclin D1 expression with HuR was found in the MDA-MB-231 cell line. Cyclin D1, which functions as a mitogenic sensor and allosteric activator of CDK4 or CDK6 (33), is one of the more frequently altered cell cycle regulators in cancers (20). Cyclin D1 mRNA, as a target mRNA of HuR, has been found to be bound and stabilized by HuR (25). Cyclin D1 overexpression is implicated as a driving feature in various types of cancer, including non-small cell lung cancer (34), breast cancer (35), and oesophageal cancer (36). Cyclin D1 overexpression in human tumors is driven by multiple mechanisms comprising genomic alterations, post-transcriptional regulation, and post-translational protein stabilization (20). Based on these findings and the present results, we support the association of HuR's effect on tumor cell growth with cell cycle regulator cyclin D1, and suggest that HuR may influence the growth rate of breast cancer cells in vitro through the regulation of cyclin D1.

Previous studies have highlighted the importance of MMP-9 in cancer cell invasion and metastasis (21) and the ability of HuR to stabilise MMP-9 mRNA (32). Thus, to clarify whether HuR's influence over MMP-9 is responsible for the reduced invasion seen here in MDA-MB-231 cells we examined the levels of MMP-9 expression at both transcript and protein level in control and HuR suppressed breast cancer cells. The data indicated that there was a significant decrease of MMP-9 mRNA in MDA-MB-231 ${ }^{\text {HиR ко }}$ cells compared to MDA-MB-231 ${ }^{\mathrm{WT}}$ and MDA-MB-231 ${ }^{\mathrm{pEF} 6}$ cells, concordant with this decrease in the mRNA level, a decrease in protein level was also seen. These results further support the role of HuR in stabilizing expression levels of MMP-9 and suggest that in the aggressive MDA-MB-231 breast cancer cell line this mechanism may be responsible, at least partially, for the reduced invasiveness seen in HuR knockdown cells. Together, this study suggests a role of HuR in the enhancement of cellular invasion, a key event in invasion and metastasis of breast cancer, and implies that HuR may affect the cellular invasion of breast cancer cells by regulating MMP-9.

In summary, our studies indicate that HuR can enhance breast cancer cell growth and invasion in vitro and this appears to be facilitated by changes in the level of cyclin D1 and MMP-9. Additional research using in vivo models is required to fully elucidate the mechanisms and role(s) of HuR in breast carcinogenesis and tumor progression.

\section{Acknowledgements}

Dr Z. Yuan, current in Beijing Friendship Hospital is a recipient of Cardiff University China Medical Scholarship. The authors wish to thank the Albert Hung Foundation, Cancer Research Wales and Beijing Friendship Hospital Research Fund for supporting their work.

\section{References}

1. Ma WJ, Cheng S, Campbell C, Wright A and Furneaux H: Cloning and characterization of HuR, a ubiquitously expressed Elav-like protein. J Biol Chem 271: 8144-8151, 1996.

2. Ma WJ and Furneaux H: Localization of the human HuR gene to chromosome 19p13.2. Hum Genet 99: 32-33, 1997.

3. Yao KM, Samson ML, Reeves R and White K: Gene elav of Drosophila melanogaster: a prototype for neuronal-specific RNA binding protein gene family that is conserved in flies and humans. J Neurobiol 24: 723-739, 1993.

4. Peng SS, Chen CY, Xu N and Shyu AB: RNA stabilization by the AU-rich element binding protein, HuR, an ELAV protein. EMBO J 17: 3461-3470, 1998.

5. Okano HJ and Darnell RB: A hierarchy of Hu RNA binding proteins in developing and adult neurons. J Neurosci 17: 30243037, 1997.

6. Brennan CM and Steitz JA: HuR and mRNA stability. Cell Mol Life Sci 58: 266-277, 2001.

7. Inoue M, Muto Y, Sakamoto H and Yokoyama S: NMR studies on functional structures of the AU-rich element-binding domains of Hu antigen C. Nucleic Acids Res 28: 1743-1750, 2000.

8. Beckel-Mitchener AC, Miera A, Keller R and PerroneBizzozero NI: Poly(A) tail length-dependent stabilization of GAP-43 mRNA by the RNA-binding protein HuD. J Biol Chem 277: 27996-28002, 2002.

9. Myer VE, Fan XC and Steitz JA: Identification of HuR as a protein implicated in AUUUA-mediated mRNA decay. EMBO J 16: 2130-2139, 1997. 
10. Bakheet T, Williams BR and Khabar KS: ARED 2.0: an update of AU-rich element mRNA database. Nucleic Acids Res 31: 421-423, 2003.

11. Antic D and Keene JD: Embryonic lethal abnormal visual RNA-binding proteins involved in growth, differentiation, and posttranscriptional gene expression. Am J Hum Genet 61: 273-278, 1997.

12. Fan XC and Steitz JA: Overexpression of HuR, a nuclearcytoplasmic shuttling protein, increases the in vivo stability of ARE-containing mRNAs. EMBO J 17: 3448-3460, 1998.

13. Zuker M: Mfold web server for nucleic acid folding and hybridization prediction. Nucleic Acids Res 31: 3406-3415, 2003.

14. Jiang WG, Davies G and Fodstad O: Com-1/P8 in oestrogen regulated growth of breast cancer cells, the ER-beta connection. Biochem Biophys Res Commun 330: 253-262, 2005.

15. Jiang WG, Martin TA, Lewis-Russell JM, Douglas-Jones A, Ye L and Mansel RE: Eplin-alpha expression in human breast cancer, the impact on cellular migration and clinical outcome. Mol Cancer 7: 71, 2008.

16. Sanders AJ, Parr C, Mason MD and Jiang WG: Suppression of hepatocyte growth factor activator inhibitor-1 leads to a more aggressive phenotype of prostate cancer cells in vitro. Int J Mol Med 20: 613-619, 2007.

17. Jiang WG, Hiscox S, Hallett MB, Horrobin DF, Mansel RE and Puntis MC: Regulation of the expression of E-cadherin on human cancer cells by gamma-linolenic acid (GLA). Cancer Res 55: 5043-5048, 1995.

18. Jiang WG, Hiscox S, Hallett MB, Scott C, Horrobin DF and Puntis MC: Inhibition of hepatocyte growth factor-induced motility and in vitro invasion of human colon cancer cells by gamma-linolenic acid. Br J Cancer 71: 744-752, 1995.

19. Jiang WG, Hiscox SE, Parr C, et al: Antagonistic effect of NK4 a novel hepatocyte growth factor variant, on in vitro angiogenesis of human vascular endothelial cells. Clin Cancer Res 5: 3695-3703, 1999.

20. Kim JK and Diehl JA: Nuclear cyclin D1: an oncogenic driver in human cancer. J Cell Physiol 220: 292-296, 2009.

21. Yao J, Xiong S, Klos K, et al: Multiple signaling pathways involved in activation of matrix metalloproteinase-9 (MMP-9) by heregulin-beta1 in human breast cancer cells. Oncogene 20 : 8066-8074, 2001.

22. Hanahan D and Weinberg RA: The hallmarks of cancer. Cell 100: 57-70, 2000

23. Vogelstein B and Kinzler KW: Cancer genes and the pathways they control. Nat Med 10: 789-799, 2004.
24. Lal A, Mazan-Mamczarz K, Kawai T, Yang X, Martindale JL and Gorospe M: Concurrent versus individual binding of HuR and AUF1 to common labile target mRNAs. EMBO J 23: 3092-3102, 2004

25. Wang W, Caldwell MC, Lin S, Furneaux $\mathrm{H}$ and Gorospe $\mathrm{M}$ : HuR regulates cyclin A and cyclin B1 mRNA stability during cell proliferation. EMBO J 19: 2340-2350, 2000.

26. Wang W, Yang X, Cristofalo VJ, Holbrook NJ and Gorospe M: Loss of HuR is linked to reduced expression of proliferative genes during replicative senescence. Mol Cell Biol 21: 5889-5898, 2001.

27. Sheflin LG, Zou AP and Spaulding SW: Androgens regulate the binding of endogenous HuR to the AU-rich 3'UTRs of HIF-1alpha and EGF mRNA. Biochem Biophys Res Commun 322: 644-651, 2004.

28. Esnault S and Malter JS: Hyaluronic acid or TNF-alpha plus fibronectin triggers granulocyte macrophage-colony-stimulating factor mRNA stabilization in eosinophils yet engages differential intracellular pathways and mRNA binding proteins. J Immunol 171: 6780-6787, 2003.

29. Levy NS, Chung S, Furneaux H and Levy AP: Hypoxic stabilization of vascular endothelial growth factor mRNA by the RNA-binding protein HuR. J Biol Chem 273: 6417-6423, 1998.

30. Tran H, Maurer F and Nagamine Y: Stabilization of urokinase and urokinase receptor mRNAs by HuR is linked to its cytoplasmic accumulation induced by activated mitogen-activated protein kinase-activated protein kinase 2. Mol Cell Biol 23: 7177-7188, 2003.

31. Lopez de Silanes I, Zhan M, Lal A, Yang X and Gorospe M: Identification of a target RNA motif for RNA-binding protein HuR. Proc Natl Acad Sci USA 101: 2987-2992, 2004.

32. Lopez de Silanes I, Lal A and Gorospe M: HuR: post-transcriptional paths to malignancy. RNA Biol 2: 11-13, 2005.

33. Sherr CJ: Mammalian G1 cyclins. Cell 73: 1059-1065, 1993.

34. Jin M, Inoue S, Umemura T, et al: Cyclin D1, p16 and retinoblastoma gene product expression as a predictor for prognosis in non-small cell lung cancer at stages I and II. Lung Cancer 34: 207-218, 2001

35. Barnes DM and Gillett CE: Cyclin D1 in breast cancer. Breast Cancer Res Treat 52: 1-15, 1998.

36. Shamma A, Doki Y, Shiozaki H, et al: Cyclin D1 overexpression in esophageal dysplasia: a possible biomarker for carcinogenesis of esophageal squamous cell carcinoma. Int J Oncol 16: 261-266, 2000. 